\title{
The association between handwashing practices and illness symptoms among college students living in a university dormitory
}

Jyothi Thumma, MPH, Allison E. Aiello, PhD, MS, and Betsy Foxman, MSPH, PhD Ann Arbor, Michigan

\begin{abstract}
We describe handwashing practices, the association of handwashing with upper respiratory and gastrointestinal symptoms, and the effects of gender on handwashing practices among male $(n=215)$ and female $(n=243)$ college students. Self-reported frequency of handwashing was not associated with infectious illness symptom reporting. Only a small proportion of males $(10 \%)$ and females $(7 \%)$ reported "always" washing their hands before eating. Females were more likely than males to always wash their hands after urinating $(69 \%$ vs $43 \% ; P<.0001)$ and after a bowel movement $(84 \%$ vs $78 \% ; P=.14)$. Identifying new strategies to increase handwashing may help prevent infectious disease transmission in residence hall environments. (Am J Infect Control 2008; :-man-m.)
\end{abstract}

Handwashing prevents the direct transfer of infectious pathogens on the hands from reaching a portal of entry and the indirect transfer through food preparation and fomite transmission pathways. ${ }^{1,2}$ Handwashing may make the difference between a successful recovery and a health care-associated infection, which account for $\sim 1.7$ million infections and 99,000 associated deaths each year in American hospitals alone. ${ }^{3} \mathrm{Al}-$ though several studies have examined handwashing in daycare centers and elementary schools, ${ }^{4-8}$ few studies have been conducted in college-aged students. One study of 391 students living in 4 university residence halls used an educational message campaign to promote hand hygiene. ${ }^{9,10}$ Students in the experimental group washed their hands and used gel sanitizers more often than those in the control group and reported significantly fewer upper respiratory illness symptoms. Several design issues limit the inference of these study findings, however, including lack of

From the Department of Epidemiology, University of Michigan School of Public Health, Ann Arbor, MI.

Address correspondence to Betsy Foxman, MSPH, PhD, Department of Epidemiology, University of Michigan School of Public Health, 109 Observatory Street, Ann Arbor, MI 48109-2029. E-mail: bfoxman@umich.edu.

This work was supported in part by the National Institutes of Health (grant ROIAI05I675) and the Center for Molecular and Clinical Epidemiology of Infectious Diseases.

0196-6553/ $\$ 34.00$

Copyright (c) 2008 by the Association for Professionals in Infection Control and Epidemiology, Inc.

doi:10.1016/j.ajic.2007.12.008 formal randomization and adjustment for clustering of subjects within a residence hall.

In the present study, we evaluated handwashing practices among 468 college students, the association with upper respiratory and gastrointestinal symptoms, and the effects of gender on handwashing practices.

\section{METHODS}

Handwashing practices were assessed among participants in a study of group B Streptococcus. ${ }^{11}$ In brief, 738 male and female college students living a single first-year dormitory at the University of Michigan, Ann Arbor during January and February 2001 were invited to participate, through a flyer placed in dormitory mailboxes. Participants were sampled by dorm floor. A total of 463 of the 738 students (63\%) elected to participate. After providing consent, each participant was given a self-administered questionnaire regarding hand hygiene practices. The study protocol was approved by the University of Michigan's Human Subjects Institutional Review Board.

\section{Data analysis}

The frequency of categorical variables, including gender, age, race/ethnicity, antibiotic use, and different handwashing practices, was evaluated using simple descriptive statistics and $\chi^{2}$ tests to assess differences in the proportions of participants reporting specific handwashing practices by gender. The associations between different handwashing practices were assessed using the Cochran-Armitage trend test. Associations between self-reported illness and handwashing practices were assessed using logistic regression models, with 
Table I. Self-reported frequency of handwashing practices during the previous 2 weeks, by gender, in 215 men and 243 women living in a first-year dormitory, University of Michigan, Ann Arbor, 200I

\begin{tabular}{|c|c|c|c|}
\hline Characteristic & Female, \% (n) & Male, \% (n) & $P$ value* \\
\hline \multicolumn{4}{|l|}{ Handwashing frequency } \\
\hline$\leq 3$ times/day & $24(60)$ & $42(91)$ & \\
\hline 3.1 to 5.9 times/day & $39(95)$ & $39(83)$ & $<.0001$ \\
\hline$\geq 6$ times/day & $36(88)$ & $19(4 I)$ & \\
\hline \multicolumn{4}{|c|}{ Handwashing before eating } \\
\hline Never & $7(17)$ & $8(17)$ & \\
\hline Rarely & 45 (109) & $49(105)$ & \\
\hline Frequently & $4 \mathrm{I}(99)$ & $33(72)$ & .41 \\
\hline Always & $7(18)$ & $10(21)$ & \\
\hline \multicolumn{4}{|c|}{ Handwashing after urinating } \\
\hline Never/rarely & $6(14)$ & $21(45)$ & \\
\hline Frequently & $25(61)$ & $36(77)$ & $<.0001$ \\
\hline Always & $69(168)$ & $43(93)$ & \\
\hline \multicolumn{4}{|c|}{$\begin{array}{l}\text { Handwashing after bowel } \\
\text { movement }\end{array}$} \\
\hline Never/rarely & $3(7)$ & $6(12)$ & \\
\hline Frequently & $13(31)$ & $17(36)$ & .14 \\
\hline Always & $84(205)$ & $78(167)$ & \\
\hline \multicolumn{4}{|l|}{ Good handwasher ${ }^{\dagger}$} \\
\hline No & $62(153)$ & $77(166)$ & \\
\hline Yes & $38(93)$ & $23(50)$ & .0007 \\
\hline
\end{tabular}

generalized linear mixed models to adjust for cluster sampling and control for potential confounders.

\section{RESULTS}

Overall, 246 female students and 217 male students enrolled in the study, and 243 females and 215 males reported their handwashing practices. Most participants were age 18 to 19 years and identified themselves as Caucasian (87\%). More females than males washed their hands 6 or more times per day $(36 \%$ vs $19 \% ; P<.0001)$. There were no significant differences by gender in handwashing before eating $(P=.40)$; only small proportions of males $(10 \%)$ and females $(7 \%)$ reported "always" washing their hands before eating. Females were more likely than males to report always washing their hands after urinating $(69 \%$ vs $43 \%$; $P<.0001)$ and after a bowel movement (84\% vs $78 \% ; P=.14)$ (Table 1$)$.

Because antibacterial hand soap was the only type of soap available in dormitory bathrooms, about $97 \%$ of the students reported using it. Students reported frequent use of antibacterial hand lotion (56\%). Females were more likely than males to frequently or always use antibacterial hand soap (84\% vs $75 \%$; $P=.06)$ and antibacterial hand lotion (25\% vs $12 \%$; $P<.0001)$.

\section{Association between handwashing practices and illness symptoms}

No significant associations were found between handwashing frequency and gastrointestinal, upper respiratory, urinary, or vaginal symptoms. Moreover, no statistically significant associations were found between selected general illness symptoms and good handwashing practices in both unadjusted analyses and analyses adjusted for gender, antibiotic use, antibacterial hand lotion, and recent sexual activity (Table 2). Finally, no significant associations were found between antibacterial hand soap/antibacterial hand lotion use and illness symptoms; good handwashers and others reported the same frequency of doctor visits (12\% vs $13 \% ; P=.7)$.

\section{DISCUSSION}

No statistically significant association was found between selected illness symptoms and good handwashing practices, although trends suggested some reduction in selected upper respiratory infection symptoms. Adjustment for daily handwashing frequency, antibiotic use, antibacterial hand lotion use, and recent sexual activity did not influence the effect of good handwashing practices on upper respiratory infection symptoms. Consistent with other observational studies of handwashing practices in hospitals and public areas, ${ }^{12-15}$ females were more likely to wash their hands at critical points and to wash their hands more frequently than males.

There is much controversy regarding the added benefit of handwashing for reducing respiratory illnesses, such as influenza. Some studies showed a stronger effect of handwashing in reducing gastrointestinal rather than respiratory illnesses. ${ }^{16,17}$ The multiple modes of respiratory infection transmission may render the effectiveness of handwashing interventions suboptimal unless they are combined with methods to reduce airborne or aerosol transmission. Our study found no protective effects of handwashing practices on gastrointestinal illness symptoms, however. Many gastrointestinal illnesses are food-borne and may be related to food preparation. Because these students were not preparing food, the absence of association between handwashing and gastrointestinal illness symptoms is not surprising.

Although the response rate was good for an observational study (63\%), it was lower than desirable, particularly if nonresponses were associated with both handwashing and illness reporting. We have no reason to believe that this occurred, however. Other factors that we did not assess, such as frequency of showering and the cleanliness of the immediate living environment, also may be associated with illness. 
Table 2. Associations among selected symptoms and good handwashing practices adjusted for gender, antibiotic use, antibacterial hand lotion, and recent sexual activity in 215 men and 243 women living in a first-year dormitory, University of Michigan, Ann Arbor, 200I

\begin{tabular}{|c|c|c|c|c|c|}
\hline \multirow[b]{3}{*}{ General symptom } & \multirow{2}{*}{\multicolumn{2}{|c|}{ Good handwasher* }} & \multicolumn{3}{|c|}{ Association of good handwashing with symptom } \\
\hline & & & \multirow{2}{*}{$\begin{array}{c}\text { Overall } \\
\text { OR }(95 \% \mathrm{CI})\end{array}$} & \multirow{2}{*}{$\frac{\text { Females }}{\text { OR }(95 \% \mathrm{CI})}$} & \multirow{2}{*}{$\frac{\text { Males }}{\text { OR }(95 \% \mathrm{CI})}$} \\
\hline & Yes $(n=143), \%(n)$ & No $(n=319), \%(n)$ & & & \\
\hline Runny nose & $66.2(94)$ & $66.8(213)$ & $0.97(0.64$ to 1.49$)$ & $0.92(0.49$ to 1.07$)$ & $\mathrm{I} .03(0.68$ to $\mathrm{I} .56)$ \\
\hline Itchy eyes & $12.7(18)$ & $11.9(38)$ & 0.97 (0.53 to 1.79$)$ & $1.30(0.73$ to 2.31$)$ & $0.93(0.5 \mathrm{I}$ to 1.70$)$ \\
\hline Fever & $6.3(9)$ & $4.1(13)$ & 0.61 (0.25 to 1.47$)$ & 0.81 (0.34 to 1.93$)$ & $0.63(0.26$ to 1.50$)$ \\
\hline Cough & $36.2(5 \mathrm{I})$ & $34.8(111)$ & $0.98(0.65$ to 1.50$)$ & $1.29(0.87$ to 1.91$)$ & $0.94(0.62$ to 1.42$)$ \\
\hline Sore throat & $33.1(47)$ & $40.3(128)$ & $1.42(0.93$ to 2.16$)$ & $1.26(0.86$ to 1.84$)$ & $1.36(0.90$ to 2.06$)$ \\
\hline Earache & $7.0(10)$ & $9.1(29)$ & $1.42(0.66$ to 3.02$)$ & $1.53(0.77$ to 3.01$)$ & I.32 (0.63 to 2.79$)$ \\
\hline Vomiting & $5.6(8)$ & $4.4(14)$ & $0.85(0.34$ to 2.10$)$ & $1.90(0.75$ to 4.80$)$ & $0.77(0.32$ to 1.88$)$ \\
\hline Diarrhea & $21.8(31)$ & $21.9(70)$ & $1.06(0.66$ to 1.73$)$ & $1.40(0.89$ to 2.20$)$ & I.0I (0.62 to I.62) \\
\hline
\end{tabular}

$\mathrm{Cl}$, confidence interval; $\mathrm{OR}$, odds ratio.

*"Good handwashers" washed their hands "frequently/always" before eating, and "always" after urinating and after a bowel movement.

In conclusion, we found significant differences between male and female handwashing practices in our college students. Self-reported frequency of handwashing was not associated with infectious illness symptom reporting. Less than half the students frequently or always washed their hands before eating. Identifying new strategies to increase handwashing may help prevent infectious disease transmission in residence hall environments.

\section{References}

I. Centers for Disease Control and Prevention and Department of Health and Human Services reports. Available from: http: //www.cdc.gov/od/oc/media/pressrel/r2k0306c.htm. Accessed January 16, 2006.

2. Katz JD. Hand washing and hand disinfection: more than your mother taught you. Anesthesiol Clin North Am 2004;22:457-7I.

3. Centers for Disease Control and Prevention. Estimates of healthcareassociated infections. Available from: http://www.cdc.gov/ncidod/ dhqp/hai.html. Accessed November 20, 2007.

4. Hammond B, Ali Y, Fendler E, Dolan M, Donovan S. Effect of hand sanitizer use on elementary school absenteeism. Am J Infect Control 2000;28:340-6.

5. Guinan M, McGuckin M, Ali Y. The effect of a comprehensive handwashing program on absenteeism in elementary schools. Am J Infect Control 2002;30:217-20

6. Carabin H, Gyorkos TW, Soto JC, Joseph L, Payment P, Collet J-R. Effectiveness of a training program in reducing infections in toddlers attending day care centers. J Epidemiol 1999;10:219-27.
7. St Sauver J, Khurana M, Kao A, Foxman B. Hygiene practices and acute respiratory illness in family and group day care homes. Public Health Rep 1998; I | 3:544-5I.

8. Niffingger JP. Proper handwashing promotes wellness in child care. J Pediatr Health Care 1997; II:26-31.

9. White C, Kolble R, Carlson R, Lipson N. The impact of a health campaign on hand hygiene and upper respiratory illness among college students living in residence halls. J Am Coll Health 2005;53:175-8I.

10. White C, Kolble R, Carlson R, Lipson N, Dolan M, Ali Y, et al. The effect of hand hygiene on illness rate among college students in university residence halls. Am J Infect Control 200I;31:364-70.

II. Manning S, Neighbors K, Tallman P, Gillespie B, Marrs C, Brochardt S, et al. Prevalence of group B Streptococcus colonization and potential for transmission by casual contact in healthy young men and women. Clin Infect Dis 2004;39:380-8.

12. Bawer P. Wash your hands! Health Mate health promotion newsletter. Available from: http://foodsafety.wisc.edu/consumer/food_facts_archive/ foodfacts_2000/foodfacts_oct_2000.htm\#hand. Accessed January 16, 2006.

13. Edwards D, Monk-Turner E, Poorman S, Rushing M, Warren S, Willie J. Predictors of hand-washing behavior. Soc Behav Person 2002;30: 75I-6.

14. Van de Mortel T, Bourke R, McLoughlin J, Nonu M, Reis M. Gender influences handwashing rates in the critical care unit. Am J Infect Control 2001;29:395-9.

I5. Van de Mortel T, Bourke R, Fillipi L, McLoughlin J, Molihan C, Nonu M, et al. Performance feedback should be repeated within a year to maximize handwashing rates in the critical care unit. Aust Crit Care 2000;13:91-5.

16. Aiello AE, Larson EL, Levy SB. Consumer antibacterial soaps: effective or just risky? Clin Infect Dis 2007;45(Suppl 2):SI37-47.

17. Aiello $A E$, Larson EL. What is the evidence for a causal link between hygiene and infections? Lancet Infect Dis 2002;2:103-10. 